\title{
APLICAÇÃO DO PROCESSO DE ENFERMAGEM AO CUIDADO DO PACIENTE NA UNIDADE DE CENTRO CIRÚRGICO
}

Brigitta E. Pfeiffer Castellanos *

CAŚtEllaNOS , B. E. P. Aplicação do processo de enfermagem ao cuidado do paciente na unidade de centro cirúrgico. Rev. Esc. Enf. USP., 12 (3): 170 - 186, 1978.

$O$ presente artigo propõe-se a abordar a aplicação do processo de enfermagem ao cuidado do paciente na unidade de centro cirirgico, partindo de uma fundamentação teórica e ilustrando a sua implementação com exemplos da prática clinica.

\section{INTRODUÇÃo}

0 processo de enfermagem ${ }^{9}$ é um conceito aceito, a nível internacional e nacional, para o provimento de cuidado qualificado, devendo ser uma parte integrante da Enfermagem atual. 0 COFEN já elaborou um projeto de lei no qual o enfermeiro terá responsabilidade legal na elaboraçáo de planos de cuidados para os pacientes a seu cargo. Segundo o Jornal Brasileiro de Enfermagem ${ }^{10}$, em todas as unidades hospitalares do INAMPS será implantado, ainda este ano, o processo de enfermagem; o objetivo visado pela Secretaria de Assistência Médica de autarquia é "melhorar o atendimento dos beneficiários, com valorização das (os) profissionais". A literatura, principalmente estrangeira, traz várias documentaçð̃es da implementação deste método científico ao cuidado dos pacientes, além de vários estudos teóricos sobre o tema.

Quando se analisa as principais variáveis que influenciam a qualidade e o nível de eficiência do trabalho, os resultados são reduzidos, segundo CHRISTMAN $^{5}$, a uma variável universal - a competência do pessoal. 0 mesmo autor argumenta, ainda, que os indivíduos tendem a interpretar seu processo de trabalho de acôrdo com seu "background" específico de treinamento e experiencia, e que na medida em que as pessoas se mantiverem sempre dentre as normas estabelecidas, o que elas fazem torma-se correto mais por definição do que por explicaçð̃es baseadas em cânones da ciência.

Prestar cuidado de enfermagem planejado e individualizado numa base sistemática é já bem aceito teoricamente; a despeito deste apoio, sistemas efetivos de planejamento de cuidado incorporados em padrões para serviços de enfermagem organizados aparecem esporadicamente, e, talvez, ainda estes existam mais em nome do que na realidade, como bem comentam LITTLE \& CARNEVALLI ${ }^{15}$.

* Professor Assistente da disciplina Enfermagem em Centro Cirúrgico da EEUSP. 
"Entusiasmo momentâneo, pouca influência eın suas instituições de trabalho, desenvolvimento inadequado de habilidade em planejamento de cuidado e falha na manutenção de seu ponto de vista frente às rotinas pressionantes do trabalho diário, tornam difícil a implementação de uma boa e freqüentemente bem aceita idéia, tal como a aplicaçæo do processo de enfermagem ao cuidado do paciente" (CHRISTMAN).

0 enfermeiro de centro curúrgico precisa reconhecer que, como um profissional, ele é responsável por sua prática; ele precisa livrar-se de seu papel meramente técnico e integrar-se no cuidado total do paciente cirúrgico, lembrando-se que em poucas ocasiōes o indivíduo está tăo dependente de outros, com relação d̀ sua segurança e bem estar, como no período anestésico-cirúrgico de seu tratamento e assistência hospitalar.

A utilizaçăo do processo de enfermagem no centro cirúrgico ajuda a assegurar um cuidado de enfermagem personalizado, contínuo e integrado. Os passos do processo de enfermagem claramente demonstram o papel e a função do enfermeiro de centro cirúrgico, como um membro profissional da equipe cirurgica e como um componente do sistema de cuidado à saúde.

Existe uma grande diferença, como bem frisa CHRISTMAN 5 na qualidade do cuidado que deriva da utilização de conhecimentos e habilidades, num processo cient ífico comparada com o cuidado pouco criativo que geralmente é o resultado do comportamento automático, tarefa centrada, que se pode denoıninar de "prática reflexa".

\section{PROCESSO DE ENFERMAGEM}

"O processo de enfermagem é uma atividade comportamental e intelectual claramente definida" (ROZMAN) ${ }^{20}$. E uma abordagem sistemática de resoluçåo de problemas ao cuidado de enfermagem. “ $E$ uma maneira ondenada e sistemática de determinar o problema do cliente (isto $\hat{\epsilon}$, avaliando e atingindo um diagnóstico) fazendo planos para resolvê-los, executar o plano ou determinar outros para executá-ło, e avaliar a efetividade do plano na resolução dos problemas identificados " (MAHOMET) ${ }^{16}$. "Ê a dinâmica das açôes sistematizadas e interrrelacionadas que visa a assistência ao indivíduo, familia e comunidade" (HORTA) ${ }^{9}$.

Sua aplicação ao cuidado do paciente requer primeiramente a coleta de dados. Estes posteriormente serão organizados em diretrizes significativas e avaliados de modo a se poder chegar a conclusōes lógicas; a intervenção de enfermagem para atingir as necessidades do paciente é baseada nestes fatos. 0 processo de enfermagem é, portanto, "o processo de organizar o cuidado paciente-centrado de um modo lógico e sistemático, por meio de avaliação, planejamento, intervenção e reavaliação ( FEHLAU ${ }^{77}$, MAHOMET $^{16}$ ).

A utilização sistemática de um método científico (o processo de enfermagem) no cuidado de enfermagem ao paciente, năo só é requisito essencial à segurança do indivíduo e à eficiência deste cuidado. como também é 
conseqüente à necessidade de Enfermagem assumir a responsabilidade de documentar e avaliar os serviços que ela presta. Como bem alertam WIGGINS \& CARTER $^{25}$ "a documentação e avaliação dos serviços prestados pelo entermeiro é requisito essencial para a Enfermagem como profissăo; se desejarmos reter a responsabilidade das açð̃es de enfermagem nós precisamos ser capazes de apresentar nossos padrões de cuidado ao paciente de uma maneira formal e providenciar instrumentos para avaliar o cuidado d luz destes padróes; sem isto nós não poderemos assumir o verdadeiro status de profissão liberal".

Numerosos artigos na literatura de enfermagem , estrangeira e nacional, indicam que o processo de enfermagem é um conceito aceito para o provimento de cuidado qualificado, e que ele é ( ou deveria ser) uma parte integrante da Enfermagem atual e é flexível para adaptar-se a uma variedade de campos clínicos, inclusive a Unidade de Centro Cirúrgico. Administrativamente a finalidade da Unidade de Centro Cirúrgico é proporcionar ao paciente uma intervenção cirúrgica da maneira mais eficiente e segura possivel, e cabe à equipe de enfermagem proporcionar condiços para o seguro e eficiente cuidado de enfermagem ao paciente durante o periodo transoperatório. SHAW ${ }^{21}$ declara: "a utilização do processo de enfermagem no centro cirúrgico é de certo modo um retorno d̀ enfermagem paciente-centrado, em lugar da enfermagem tarefa-orientada". HOOPES \& MCCONNELL ${ }^{8}$ alertam: "em nossa luta para identificar nosso papel como enfermeiros, nós precisamos pensar em termos de cuidado ao papaciente, mais do que em termos de procedimentos cirúrgicos; nós precisamos demonstrar que nós não desejamos unicamente assistir nosso paciente na busca de uma melhor condição de saúde ajudando o cirugião, mas também, assumindo a responsabilidade de seu cuidado enquanto está em nossa área"

${ }_{\text {menta } \mathrm{FEHLAU}^{7}} \mathrm{O}^{2}$ enfermeiro de centro cirúrgico é mais conhecido, como coenfermagem precisando ser executadas com segurança, inteligência e julgamento, discriminatório; mas, como alertam WELSH \& RICHARDSON ${ }^{24}$, "freqüentemente é dito que enfermeiros de centro cirúrgico existem porque demonstram uma maior aptidão para a destreza manual do que a habilidade e simpatia requerida para o enfermeiro de unidade de internaçåa"; aceitam estas autoras que esta declaração pode ter algum elemento de verdade para alguns enfermeiros, mas que ela geralmente não é verdadeira pois " é a combinação de duas qualidades que produz um enfermeiro que é competente em centro cirúrgico: uma é ser proficiente em habilidades técnicas requeridas e outra, a mais importante, é o enfermeiro othar dentro da área cirúrgica em si e tomar-se envovido no conceito de cuidado total do paciente" 24 .

Esta abordagem de cuidado de enfermagem deve ser estimulada nos enfermeiros de centro cirúrgico a fím de que não esqueçam a arte de relacionamento com seus pacientes para conseguirem sua confiança e confidência; necessário que seja enfatizado que os enfermeiros de centro cirúrgico não são engajados, unicamente em atividades técnicas a fim de que possam ser de maior benefício para seus pacientes e para que consigam um maior grau de satisfação no trabalho pelo desenvolvimento equilibrado de suas habilidades nas duas áreas de assistência de enfermagem :na área instrumental (necessidades fisiológicas) e na 
área expressiva (necessidade psico-espirituais e sociais).

Como bem lembra RIDGEWAY ${ }^{18}$ " "o enfermeiro precisa

mover-se dos aspectos puramente técnicos da enfermagem em centro cirúrgico para um papel onde ele utilizará seu conhecimento especializado e julgamento profissional na avaliação dos problemas dos pacientes e na execução das ações de enfermagem". Para a intervenção de enfermagem o enfermeiro de centro cirúrgico precisa levar em conta problemas fisiológicos, sociais e comportamentais que afetam ou resultam da resposta individual e/ou da adaptação à intervençà cirúrgica.

A Associação dos Enfermeiros de Centro Cirúrgico dos E.U.A. (AORN) lembra que: o cuidado de enfermagem em centro cirúrgico será sempre paciente - centrado, estando o paciente consciente, semi-consciente ou inconsciente, desde que proporcione: respeito pelo indivíduo com proteção a seus direitos humanos e dignidade; satisfaçẫo das necessidades humanas básicas individuais psicológicas, psico-sociais e psico-espirituais; prevenção de acidentes e lesões possíveis de acontecer por omissão ou comissão; estado de alerta e proteção contra os perigos peculiares de um ambiente específico e/ou procedimentos peculiares".

A aplicação do processo de enfermagem na Unidade de Centro Cirúrgico, portanto, provê ao enfermeiro com um método sistemático de prestar cuidado de enfermagem, tanto individualizado como rotineiro, a paciente durante o período transoperatorio. "As atividades de enfermagem são dirigidas a provisão de continuidade de cuidados através da avaliação e prẹparação pré-operatória, intervenção intraoperatória e avaliação posoperatória" 23 . Através desta abordagem de resolução de problemas, necessidades de cuidados de enfermagem são identificados, cuidado é planejado e implementado, e resultados dos cuidados podem ser avaliados.

Os passos principais do processo de enfermagem são: coleta de dados, planejamento e implementação do cuidado de enfermagem, e avaliação dos resultados do cuidado prestado.

\section{PASSO: COLETA DE DADOS.}

O primeiro passo da aplicação do processo de enfermagem ao cuidado do paciente será, portanto, a coleta de dados.

Para pensarmos no paciente como uma pessoa, precisamos de uma oportunidade para conheck to como tal; geralmente quando o recebemos na Unidade de Centro Cirúrgico as únicas informaçoes que possuimos sa as constantes na escala cirúrgica e na ficha ou formulário de cirurgia, os quais poucos informes trazem sobre o paciente. A falta de disponibilidade de tempo para consulta do prontuário medico enviado pelo pessoal da unidade de internaçã̃o, acrescida da inconveniência de se efetuar no recebimento do paciente uma entrevista produtiva por ele estar sob o efeito da medicação pré-anestésica e/ou de produzir fatores estressantes, acarreta a necessidade de uma anterior avaliação pré-operatória sistemática do paciente cirúrgico.

Esta avaliação pré-operatória do paciente pelo enfermeiro de centro cirúrgico inclui a coleta de dados relativa a sua pessoa , ao seu estado de 
saúde e de doença e a identificação de problemas diretamente relacionados com a experiência anestésico-cirúrgica. Os dados são colhidos do prontuário médico, do Histórico de Enfermagem da Unidade de Internação (quando existente), por observacão direta e por entrevista com o paciente e/ou seus familiares. JOUCLAS ${ }^{11}$ preconica a utilização da sua "ficha pré-operatória de enfermagem" com o objetivo de estabelecer um intercâmbio de informações entre as unidades de internação e de centro cirurgico.

Segundo FEHLAU ${ }^{7}$, a avaliação pré-operatória sistemática é a chave da efetividade do processo de enfermagem pois "a coleta de dados acurados é essencial ao planejamento de intervenções personalizadas, antes e durante a cirurgia ; o conhecimento das respostas normais e usuais do indivíduo é vital para a identificaçăo de alteraçōes e interpretaçōes de respostas comportamentais e físicas do paciente durante sua permanência no centro cirúrgico". Assim, a individualização dos cuidados de enfermagem torna-se uma realidade pois "os cuidados serẫo baseados em profundas informações e não em procedimentos indicados em uma lista cirúrgica " (CLEMONS 4 ).

Esta fase é a de responsabilidade do enfermeiro, não podendo ser delegada a outros membros da equipe de enfermagem, pois exige capacidade de julgamento, conhecimento científico e poder de decisáo. Durante a avaliaçáo pré-operatória o enfermeiro do centro cirúrgico utiliza habilidades comportamentais e conhecimentos relativos ao comportamento humano frente à saúde e doença; a interpretaçăo dos dados e a identificação de problemas específicos ao cuidado de enfermagem no centro cirúrgico requer conhecimento adicional acrca de cuidados especiais relacionados ao ato anestésico-cirúrgico.

A anotaçato dos dados e dos problemas identificados (por meio de comunicações escritas e/ou verbais e por observação) é realizada num instrumento específico do centro cirúrgico para coleta de dados; este pode ser uma adaptação do Histórico de Enfermagem da Unidade de Internaça ou um instrumento próprio da Unidade de Centro Cirúrgico. A utilizaçăo deste instrumento específico do centro cirúrgico facilitará o processo de avaliaç̧̃o pré-operatória, providenciando um sistema organizado para assegurar informaçōes apropriadas ao cuidado do paciente nesta Unidade.

Fatores significantes da avaliaçăo pré-operatória do paciente cirúrgico são indicados em tal formulário, tais como:

-. dados sobre sua pessoa, através da identificação (necessitamos saber algo sobre o passado cultural do paciente, tal qual como:se é estrangeiro, qual sua vivência social, seu nível de compreensão, se é sua primeira hospitalização ou sua primeira experiência anestésico - cirúrgica);

- dados sobre seu estado biológico, através do exame físico e dos resultados dos : exames laboratoriais, tais como: estará anêmico ? terá enfisema, bronquite, asma ? é fumante, alcoolista ou dependente de dro- 
gas ? é alérgico? tem infeç̧åo ? tem problemas físicos que interferirão no ato cirúrgico, no posicionamento, na anestesia, na comunicaçăo ou no transporte? necessitara de algum instrumento de tamanho ou caracteristicas especiais ?;

- dados sobre sua doença e tratamento cirúrgico poposto, através dos dados médicos, tais como: moléstia e cirurgia proposta, sintomas que possam determinar cuidados de enfermagem especiais;

- dados sobre seu estado psicologico e espiritual, através da expectativa e percepfäo do paciente, tais como: como se sente diante do diagnóstico e tratamento proposto? do prognóstico? da hospilização? da participaça do plano terapéutico?

A biteratura especializada publicada em revista de enfermagem, principalmente americana e ingleas, preconiza, já há muito tempo,a realizaça da visita pré-operatória do enfermeiro do centro cinirgico com o intuito de favorecer a continuidade do cuidado de promover a interaçăo enfermeiro-paciente. A utilidade e a validade desta interaço tem sido alvo de inúmeros trabalhos, descritivos e experimentais, conduindo-se ser ela produtiva tanto para o paciente como para o enfermeiro de centro cirúrgico. E necessário aclarar, como bem lembraram HOOPES \& McCONNELL ${ }^{8}$, que visitando o paciente nós nã̃o estaremos usurpando o papel de orientaçäo pré-operatória do enfermeiro da unidade de internaçăo; nós năo iremos descrever o tratamento cirúngico, que é da alcada da equipe médica, nós iremos, sim tentar estabelecer um relacionamento com o paciente, servir como uma fonte de informaçoes para ele, e escutar o que ele tem para dizer. " Nos podemos dar-the a atenç̧o de uma visita pessoal e 0 benefício, de nossa especialidade profissional" 8 .

HOOPES \& MCCONNELL 8 opinam que "o paciente freqüentemente hesita fazer perguntas so pessoal de enfermagem da unidade de intemaçăo devido do desejo de ser o "paciente ideal", de năo ser " importunador",e que desde que o enfermeiro de centro cirlingico vai especificimente para responder ds suas perguntas, ele pode sentir-e mais livre para tomarthe a tempo, sem sentir que o está mantendo longe de seus afazeres ou de doentes mais graves que - necessitam mais; ele pode fazer perguntas especificas acerca da sala de operapóes que o enfermeiro da unidade de internaço pode nžo estar apto a respon der".

E valido lembrar que geralmente pensace em membros da equipe cirurgic como sendo o cirurgilo, seu assistente, o anestesista, o enfermeiro de centro cirúrgico e o circulante de sala de operagóes; mas o paciente, como bem lembra BARNETT ${ }^{2}$, também, pode tornarse um importante membro desta equipe e sua maior contribuiçăo sert o de estar na melhor condiç̧̃o possível para a operaçåo e para a recuperaça posoperatória. Para isso é necessário um preparo não s6 físico mas também psicoespiritual pois é teoria irrefutável que a cirurgia representa uria fonte de estresse em potencial que influencia grandemente $o$ ato cirúrgico, a anestesia e a evoluçăo posoperatoria.

Os receios, concretos ou infundados, geralmente sto fontes de ansiedade para o paciente; săo gerados, como analisa EPSTEIN ${ }^{6}$, pela sensaça 
de insegurança e impotência, comuns ao papel de "paciente " do indivíduo internado; a esta situação soma-se ainda a repercussão psicológica de um tratamento cirúrgico, no qual, como comenta KATZ 13 "estão associados dois seres , dos quais um coloca sua vida nas mã̃s do outro"; o mesmo autor salienta a necessidade de se levar em consideração as reaçðes a nível psicológico produzidos pela enfermidade, $O$ ato cirúrgico ou a equipe de saúde, lembrando que estas reações podem originar mudanças locais ( alterações de conduta) ou gerais (complicações muito variadas e até a morte).

Analisando os estímulos que podem agredir o paciente e originar o estado de estresse $\mathrm{KATZ}^{13}$ cita a dor, a ansiedade, o medo e outros mecanismos psicológicos e refere que uma das observações realizadas na medicina psicossomática é a da natureza específica dos estímulos emocionais que intervém nos diferentes disturbios orgânicos; analisando as teorias que tratam de explicar este problema da especificidade, 0 autor cita CANNON que diz que "a cada estado emocional corresponde uma resposta fisiológica característica; os componentes fisiológicos da angústia, por exemplo, são parecidos, mas não idênticos ao da cólera ou da ira e se expressam mediante uma combinação detranstornọs víscero-motores e tensões músculoesqueléticas manifestadas por pálpitações, transtornos respiratórios como hiperventilação, sensação de opressão no tórax e garganta, congestão facial , transpiração e sensação de debilidade com tremores, sintomas estes que se acompanham subjetivamente por intensa apreensão obsessiva e não confessada".

EPSTEIN ${ }^{6}$ advoga que a participação do paciente no que lhe interessa no seu tratamento é uma das formas de reduzir os receios infundados e que além disso," o paciente possue dados vitais para ajudar a equipe de saúde no planejamento e execução de seu tratamento: sabe como se sente em relação ao que está sendo feito com ele, sabe qual sua atitude quanto a estar enfermo quais são suas preocupações com o tratamento, com a famflia e com seu futuro. A mesma autora lembra que estes sentimentos e atitudes podem influenciar sua observância aos tratamentos propostos, seu preparo psicoespiritual para a cirurgia, sua determinação em se curar - tudo enfim o que a equipe justamente precisa para a eficiência do tratamento".

Diversos estudos estrangeiros já foram realizados comprovando que a visita pré-operatória do enfermeiro de centro cirúrgico contribui para a redução da ansiedade do paciente. No Brasil, PANZA ${ }^{17}$, em sua monografia de mestrado, demonstrou que a visita da enfermeira do centro cirúrgico, às pacientes. no pré-operatório: diminui significativamente o estresse no pré- operatório, no dia da cirurgia e no pósoperatório; permite o conhecimento da paciente, fornecendo-lhe elementos para o planejamento e execução da assistência no pré e transoperatóro.

Explicações para este fenômeno de relacionamento são dados por vários autores, tais como "o paciente sente que está recebendo a visita de alguém do centro cirúrgico , que está obtendo atenção e informação de alguém que sabe o que the vai acontecer; conhecer uma pessoa que estara junto dele durante a cirurgia ajuda ao paciente a enfrentar o desconhecido (MAHOMET) ${ }^{16}$ 
"existe um grande relacionamento entre preparo e apoio psicológico durante o período pré- operatório e redução do estresse, medido pelas respostas fisiologicas dos pacientes no pósoperatório ", $\left(\mathrm{KATZ}^{13}\right.$, PANZA ${ }^{17}$, RIDGEWAY ${ }^{18} \mathrm{e}$ SCHIMITT \& WOOLDRIDGE ${ }^{21}$ ); " o fato do paciente saber o que the acontecera num nível de necessidade individual de orientaçăo diminui sua tenșo eo toma mais adaptativo ds ocomencias estressantes (EPSTEIN ${ }^{6}$, RIDGEWAY $^{18}$ ) BOEGLI \& BOEGLI ${ }^{3}$ alertam que a presença de ansiedade ou medo no pré-operatório dos pacientes cirúrgicos cria uma barreira que dificulta a apreeensăo do que está sendo transmitido".

Do ponto de vista do enfermeiro KRAMER ${ }^{14}$ e SHAW22 sintetizaram os propositos desta avaliacato e interaçå pré-operatória: respeitar a individualidade do paciente, coletar dados, dimbuir a ansiedade que o paciente possa ter em relaço a cirungia; melhorar o cuidado pelo conhecimento do paclente e seus problemas anteriormente cinurgia; permitir 1 equipe de enfermagem ter equipamento extra, pronto para ser utilizado; auxiliar o paciente a compreeender os procedimentos e a conhecer os equipamentos que serio utilizados em seu cuidado; melhorar a comunicaclo entre o pessoal das unidades de internaçăo e de centro cirúrgico, bem como com a equipe médica; tomar o enfermeiro de centro cirángico mais envolvido com o cuidado total do paciente e ajudá-lo a manterse atualizado com os novos procedimentos e idéias; reforçar informacóes já recebidas da enfermeira da unidade de intemaça.

KAPSAR ${ }^{12}$ lembra que a visita pré-operatória ao paciente tem um papel importante no auxilio ao enfermeiro de centro cirúrgico para atingir seus objetivos profissionais e para providenciar continuidade de cuidado através de avaliaglio pré-operatória, intervençă intra-operatória e avaliaçăo posoperatória.

Na impossibilidade do enfermeiro de centro cirangico realizar a visita pré-operatória para a avaliaçăo e interacăo com o paciente, uma alternativa seria, como primeiro passo para a melhoria da qualidade do cuidado de enfermagem, utilizaço da ficha preconizada por JOUCLAS ${ }^{11}$ e o desenvolvimento de um instrumento de comunicaglo simplificado refletindo e definindo as informaçoes bisicas desta avaliaçio, necessátias so circulante da sala de operagôes.

0 quadro I (Anexo1) mostra uma lista de problemas de enfermagem desenvolvida pelo enfermeiro de centro cirúrgico baceada nia interpretaço dos dados da ficha de JOUCLAS ${ }^{11}$ e dos dados obtidos na interaçäo enfermeiro paciente conseguida por meio da visita pre-operatória.

\section{2. $233^{\circ}$ PASSOS: PLANEJAMENTO DOS CUIDADOS DE ENFERMAGEM E IMPLEMENTAÇÃO DO PLANO.}

0 plano de cuidados de enfermagem no centro cirúrgico especifica, segundo FEHLAU', "intervençố de enfermagem para promover e imanter a seguranç e o conforto individuais, respostes e/ou adaptaçós i alteraçöes fisiologicas e alto nível de bem estar".

"E o plano organizado de cuidados para o paciente, no qual,de 
uma maneira consciente e sistemática, os problemas individuais são comunicados, ps objetivos de cuidados indicados e as agoes de enfermagem săo prescritas" 7

Merece ser lembrado que o enfermeiro de centro cirúrgico, 11der da equipe de enfermagem, so assumir a responsabilidade do paciente estar prestando esta assistência de enfermagem, dando diretamente o cuidado ou delegando a alguém sob sua direģăo, e que para tal, e de suma importância determinar no plano de cuidados que aços se deva dar prioridade e que pessoal competente para desempenhar determinada tarefa ou fungilo especifica.

1 implementagiso do plano de cuidados $t$ iniciada ja duremte a visita prt-operat6ria do enfermeiro de centro cirlungico e ce continua no decorrer de todo o tempo de permanéncia do paciente no centro cirágico. Para que ceu objetivo de favorecer a continuidade do cuidado de enfermagem seja conservada KAPSAR $^{12}$ recomenda que ele deve acompanhar o paciente dentro do centro clrúrgico, na sala de recuperagito pormeatedica e na unidade de internacio; a merma autora opina ainda que a utilistade e validade deste plano of particularmento sentida quando a pessoa designada para prestar os cuidados a paciente nibo 6 a que teve oportunidade de realizar a visita prt-operatória a este paciente. Bntesdemos que isto seja devido ds caracteriaticas de objetividade das agoes de enfermagem prescritas no plano, de modo a que qualquer peseos posea executatas.

Os objetivos dos cuidados de enfermagem podem ser eatabelocidos uma vez que os problemas foram identificados e necessidades de cuidados avaliados: os objetivos dos cuidados determinarto as açes de enfermagem que seråo implementados. FEHLAU' alerta que "estes objetivos devem ser realísticos e paciente-orientados; devem ser escritos com as declarapoes de comportamentos esperados ou resultados que refletirio a soluçio do problema; devem portanto, ser observiveis e mensuráveis pois sto os padróes pelos quaib o sucesso ou o fracasso da intervençăo de enfermagem serio medidos e avaliadoa".

O planejamento dos cuidados refletirt proridade e alternativa para aços de enfermagem| FEHLAU' ${ }^{7}$ Oplna que "um bom plano de cuidados de enfermagem permite 20 enferineiro de centro cirturejco cor criativo e inovador na promoçă do mais eficiente e efetivo cuidado de enfermagem $20 / \%$. ciente ciŕrgico na sala de operagoes". 0 quadro II (Anexo 2) mostra o plano de cuidados de enfermagem no centro cirungico.

Durante a fase de implementaçio do plano de cuidados, sao executadas as apores designadas para atingir os objetivgs deste plano, pelos diferentes membros da equipe de enfermagem. FEHLAU aclara que esta fase só termina quando as respostas do paciente da acöes de enfermagem sao observadas e relatadas num relatório permanente, que nzo só comunica informaçöes acerca do paciente ao enfermeiro da unidade de internaçă, mas também proporciona um meio para avaliar os resultados dos cuidados; estas informaçðes podem também ser um componente valioso e útil ao planejamento do cuidado posoperatório.

0 paciente é continuamente observado e avaliado, durante o tempo de sua permanência no centro cirfurgico, quanto dus respostas du açöes de enfermagem, bem como ds intervençð̃es médicas (cirúrgicas e anestésicas); săo 
controlados movimentos das extremidades corporais, presença de cianose, variaç̆o de temperatura corporal, sudorese ou pespiração intensa; é observada a perfusấ venosa, posiçōes inadequadas, olhos entreabertos e outros sinais que possam levar a possíveis complicaçōes. Condiçð̃es de alteraçōes durante a cirurgia podem requerer reavaliaçōes, com a obtençăo de novos dados e identificaçăo de outros problemas, exigindo revisão dos objetivos, implementaçăo de açỏes de enfermagem alternativas ou outras modificaçðes na abordagem do cuidado de enfermagem.

\section{4.' PASSO: AVALIAÇÃO DOS CUIDADOS DE ENFERMAGEM}

Para completar 0 processo de enfermagem aconselha-se ao enfermeiro de centro cirúgico realizar a visita posoperatória, durante a qual poderá avaliar melhor os resultados de sans açōes; esta avaliação indicará o sucesso e/ ou as falhas do processo quanto à maneira como foi desenvolvido e quanto à eff ciência das acoóes especifficas de enfermagem em atingir os objetivos propostos. RIDGEWAY ${ }^{18}$ opina que o terceiro dia de posoperatório é o mais apropriado para esta visita, a năo ser que o paciente esteja ainda na unidade de cuidados intensivos. PANZA 17 , realizando esta visita no primeiro e segundo dia de posoperatório, demonstrou através do resultado do indice de suor palmar (PSI), a possibilidade de avaliaçăo da assisténcia de enfermagem pré e transoperatória.

Nesta visita posoperatória o enfermeiro de centro cirúrgico verificará com o enfermeiro da unidade de internaç5̃o, o estado geral do paciente, observará sinais de infeç̧⿻ posoperatória, lesðes de pele pelo uso de aparelhos elétricos, alteraçóes musculares, neurológicas e/ou circulatórias por posicionamento inadequado, bem como a quantidade de análgesicos e narcóticos necesários para o controle da dor e sintomas de outras complicaçós posoperatórias como vômitos, agitaçăo, etc. Aproveita-se também esta outra oportunidade de interacaio com o paciente para verificar se suas expectativas foram atingidas e se existe alguma sugestio para melhorar o cuidado de enfermagem no centro cirúrgico.

CASTEllanOS, B. E. P. Applying the nursing process to patient care in the operating room. Rev. Esc. Enf. ISSP, I2 (3): 170 -. $186,1978$.

The article proposes to approach the application of the nursing process to patient care in the operating room, it gives a theorical hasis and examples from the clinical pratices. 


\section{REFERENCIAS BIBLIOGRAFICAS}

1 - ASSOCIATION OF OPERATING ROOM NURSES. Standards for administrative and clinical practice in the operating rooms. AORN J. , 8: $80-2$, Aug. 1968.

2 - BARNETT, L. A. Preparing your patient for the operating room. AORN J. , $18(3): 534$ - 9 Sept. 1963.

3 - BOEGLI, E. H. \& BOEGLI, R. G. Can preop learning be improved? AORN J., 16:43-5, Nov. 1972.

4 - CLEMONS, B. The OR Nurse in the patient care circuit. Am. J. Nurs. , $68(10)$ : $2141-$ A, Oct. 1968.

5 - CHRISTMAN, L. An all - RN or staff. AORN J., 23 (7) : 1194-7, June 1976.

6 - EPSTEIN, C. Interação efetiva na enfermagem; (trad. Efigênia Belfort Mattos et al.) São Paulo, EPU, Ed. da USP, 1977.

7 - FEHLAU, M. T. Applying the nursing process to patient care in the operating room. Nurs. Clin. North, Am. , $10(4): 617-23$, Dec. 1975.

8 - HOOPES, N. M. \& McCONNELL, M. An approach to preoperative visits. AORN J. , 26 (6): 1048 - 52, Dec. 1977.

9 - HORTA, W. de A. O processo de enfermagem: fundamentaçăo e aplicaç̧o. Enf. Novas Dimens. , 1 (1): 10 - 6, 1975.

10 - JORNAL BRASILEIRO DE ENFERMAGEM, 2 (18): 1, set. 1978.

11 - JOUCLAS, V. M. G. Elaboração e avaliação de um instrumento de comunicação que favoreça a assistência de enfermagem no transoperatório. São Paulo, 1977. (Dissertação de mestrado - Escola de Enfermagem da USP).

12 - KAPSAR, P. The preoperative visit $-0 . R$. nurses and patientes interacts. Hospitals, 50 (16): $87-8$, Apr. 1976.

13 KATZ, E. Respuesta organica a estimulos psicológicos. In: KATZ, E. et al. Pre y post operatorio normal y patologico. Buenos Aires, Endeba, 1971. V. 2 p. 907. 
14 - KRAMER, C. S. Preops: a communication technic. AORN J., 14: $66-7,1971$.

15 - LITTLED, D. \& CARNEVALLI, D. The nursing care planning system. Nurs. Outbok, 19(3): 164-67, Mar. 1971.

16 - MAHOMET, A. D. Nursing diagnosis for the OR nurse. AORN J. 22(5): 709-11, Nov. 1975.

17 - PANZA, A. M. M. Efeito da visita pré-operatória da enfemeira do Centro Cirírgico sobre o estresse do paciente no pré-operatónio, no dia da cirurgin e no posoperatório. Såo Paulo, 1977

(Dissertafizo de mestrado - Escola de Enfermagem da USP).

18 - RIDGEWAY, M. F. Preop interviews assure quality care. AORN J., 24 (6): $1083-85$, Dec. 1976.

19 - SALZANO, S. D. T. Estudo da avaliaç to e temperatura corpórea no paciente anestésico-cirárgico. São Paulo, 1972 ( Tese de doutoramento - Escola de Enfermagem da USP).

20 - ROZMAN, M. F. Nursing Process in the recovery room. AORN J.,24 (6): 1069 - 75, Dec. 1976.

21 - SCHMITT, F. E. \& WOLDRIDGE, P. J. Psychological preparation of surgical patients. Nurs. Res., 22: 108 -15, Mar./Apr. 1973.

22 - SHAW, H. The process, the operating theatre and the pattient. . NAT. News, 20 - 2 Nov. 1976.

23 - STANDARDS of nursing practice : operating room. AORN J., 24 (4): $798-808$, Oct. 1976.

24 - WELSH, J. \& RICHARDSON, A. How well do you know your patient nurse? NAT News : $12-5$, July 1976.

25 - WIGGINS, A. \& CARTER, J. H. Evaluation of nursing assessment and intervention in the surgical ICU. Nurs. Clin. North Am. , 10 (11): $121-44$, Mar. 1975. 


\section{ANEXO 1}

QUADRO I - Lista de problemas de enfermagem de centro cirúryico derivada da interpretaç̃o dos dados da ficha de JOUCLAS ${ }^{\mathrm{h}}$ e da interaçฐo enfermeiro - paciente conseguida através da visita pré-operatória.

\begin{tabular}{|c|c|}
\hline \multicolumn{2}{|c|}{ 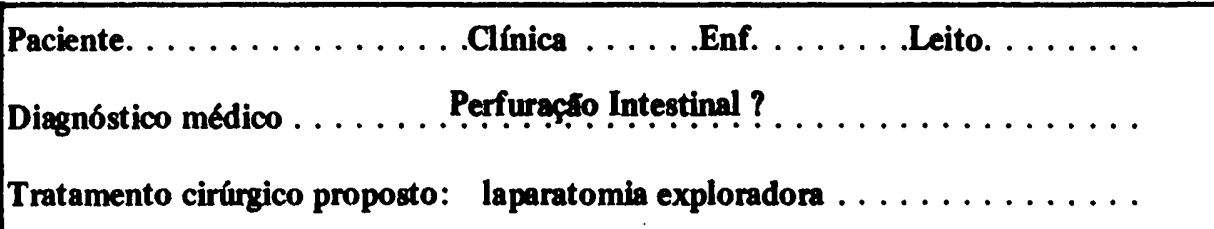 } \\
\hline problemas do paciente & problemas de enfermagem \\
\hline $\begin{array}{l}\text { 1- Ansioso devido a falta de compre- } \\
\text { ensło do procedimento cirurgico, } \\
\text { desconhecimento do prognóstico } \\
\text { e do provável tempo de hospitalł } \\
\text { zaçăo. }\end{array}$ & $\begin{array}{l}1 \text { - nivel de estresse inadequado ao } \\
\text { tratamento cirangico. }\end{array}$ \\
\hline 2 - Temperatura $=38^{3} \circ \mathrm{C}$. & 2-possível infecção. \\
\hline 3 - Peso/altura : $98 \mathrm{Kg} / 1,66 \mathrm{~m}$ & $\begin{array}{l}3 \text { - dificuldade no transporte e posi- } \\
\text { cionamento da mesa; possivel ins } \\
\text { tnumental extra para posiciona- } \\
\text { mento e cirurgia. }\end{array}$ \\
\hline 4 - Vômitos freqüentes. & 4 - depleção de fluidos corporais. \\
\hline 5 - Infusão venosa por "intracath". & $\begin{array}{l}5 \text { - dificuldade no transporte; possi- } \\
\text { bilidade de obstruço do "intra- } \\
\text { cath" }\end{array}$ \\
\hline 6- Colostomia / auto-cuidado. & $\begin{array}{l}\text { 6- possivel infecção cruzada da feri- } \\
\text { da cirargica. }\end{array}$ \\
\hline $\begin{array}{l}7 \text { - Escoriaçбes da pele ao redor da } \\
\text { colostomia. Alérgico ao espara- } \\
\text { drapo. }\end{array}$ & $\begin{array}{l}7 \text { - escoriaçes ao redor da colosto- } \\
\text { mia; impossibilidade de utilizar a- } \\
\text { desivo comum. }\end{array}$ \\
\hline 8 - Pele moderadamente limpa. & $\begin{array}{l}8 \text { - possível infecç̧̃o da ferida cirúr- } \\
\text { gica. }\end{array}$ \\
\hline 9 - Abdomen distendido e rígido. & $\begin{array}{l}\text { 9. dificuladade no transporte; pos- } \\
\text { sível infecção. }\end{array}$ \\
\hline
\end{tabular}




\begin{tabular}{|c|c|}
\hline $\begin{array}{l}10 \text { - Dentes cariados e ausência dos } \\
\text { dentes anteriores na arcada su- } \\
\text { perior. }\end{array}$ & $\begin{array}{l}10 \text { - dificuldade na entubação en- } \\
\text { dotraqueal, possível infecção } \\
\text { das vias aéreas superiores. }\end{array}$ \\
\hline $\begin{array}{l}11 \text { - Acuidade visual e auditiva } \\
\text { moderadamente diminuida. } \\
\text { Semi-analfabeto. }\end{array}$ & $\begin{array}{l}11 \text { - possíveis dificuldades na adap- } \\
\text { tação ao meio ambiente, pes- } \\
\text { soal e comunicaçæ̃o acerca de } \\
\text { cuidados e tratamentos. }\end{array}$ \\
\hline 12 - Fatiga-se com facilidade. & 12 - dificuldade no transporte. \\
\hline 13 - Alcoolista no passado. & $\begin{array}{l}13 \text { - possível resistência aos agen- } \\
\text { tes anestésicos. }\end{array}$ \\
\hline $\begin{array}{l}14 \text { - Lesסes troficas no membro } \\
\text { inferior esquendo. }\end{array}$ & $\begin{array}{l}14 \text { - dificuldadel da descarga elé- } \\
\text { trica na placa inativa da uni- } \\
\text { dade de eletro-cirurgia. }\end{array}$ \\
\hline $\begin{array}{l}15 \text { - Medo de ficar desnudo e so-. } \\
\text { zinho. }\end{array}$ & $\begin{array}{l}15 \text { - medo de ficar desnudo e so- } \\
\text { zinho. }\end{array}$ \\
\hline
\end{tabular}




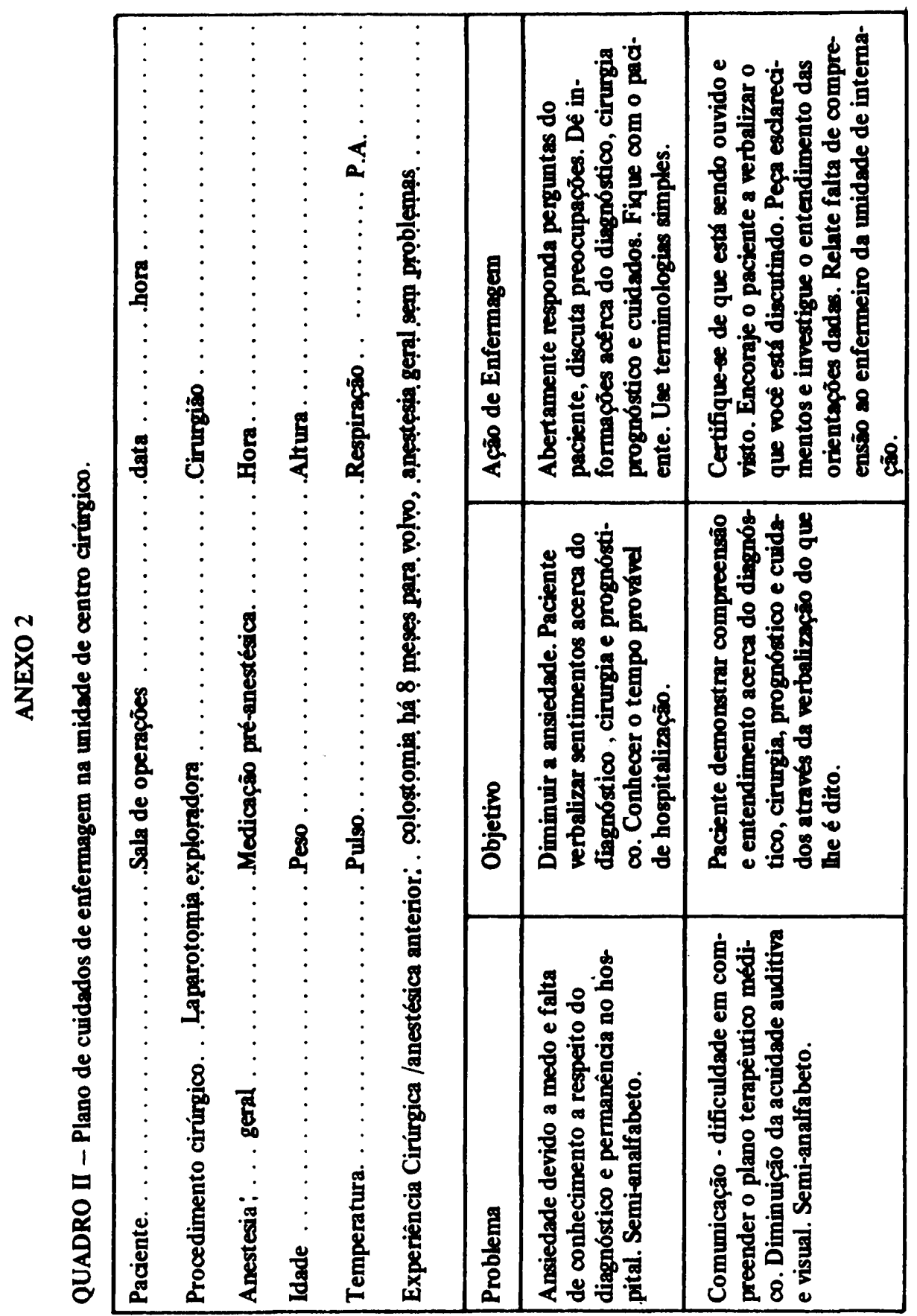




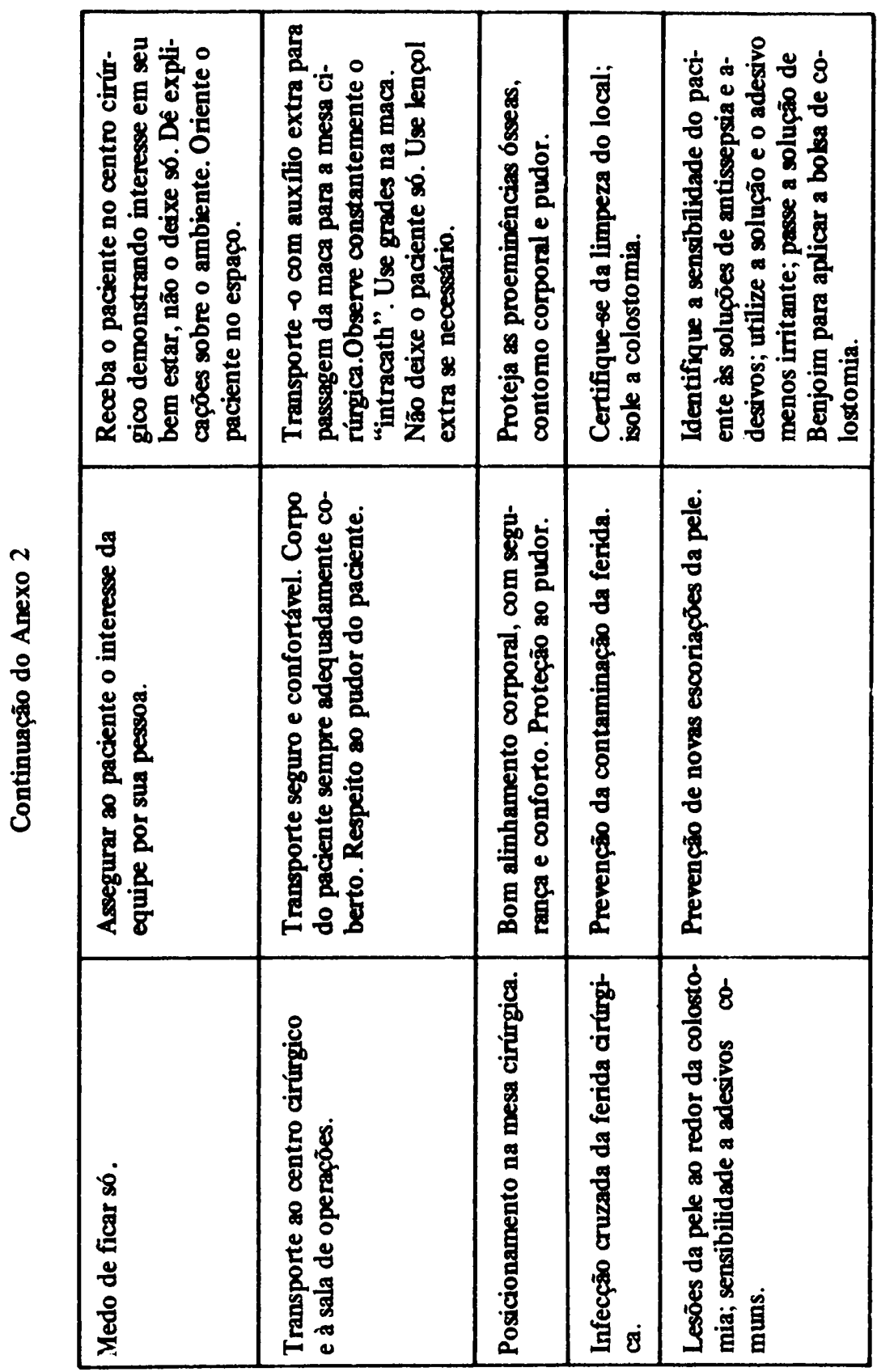




\begin{tabular}{|c|c|c|}
\hline 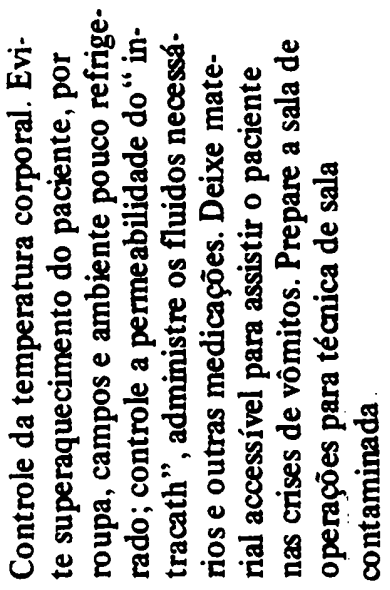 & 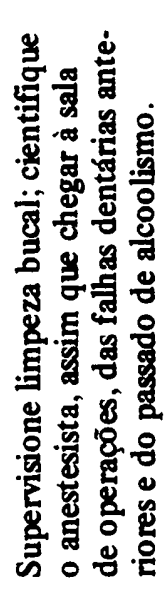 & 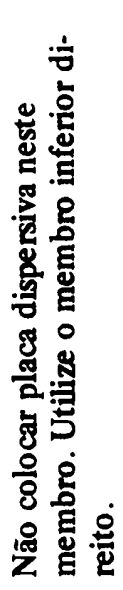 \\
\hline 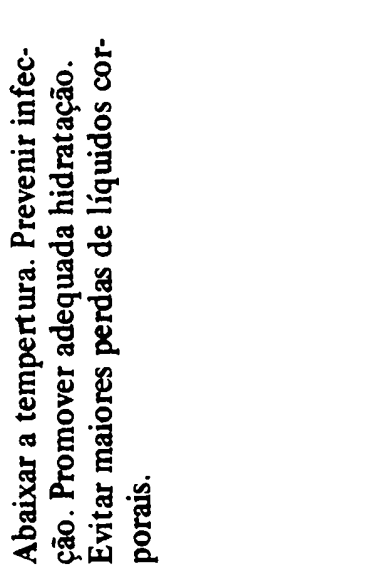 & 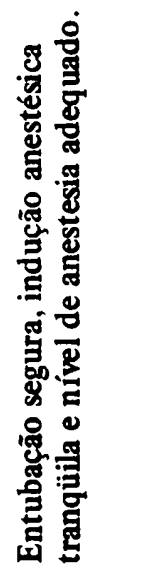 & 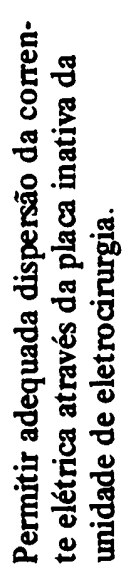 \\
\hline 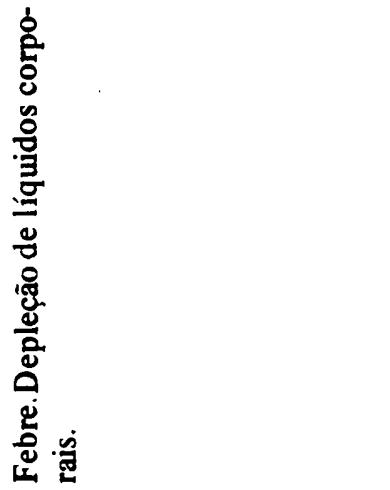 & 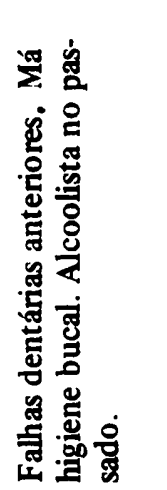 & 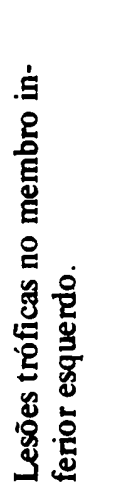 \\
\hline
\end{tabular}

